\title{
ENTREVISTA COM MARIA EMÍLIA PEREIRA CHANUT
}

\section{INTERVIEW WITH MARIA EMÍLIA PEREIRA CHANUT}

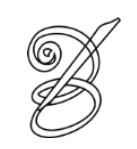

Entrevistada por:

Clarissa Prado MARINI*

Universidade de Brasília, Brasil

aria Emília Pereira Chanut ${ }^{* *}$ é doutora (2004) e mestre (2001) em Letras pela
Universidade Estadual Paulista Júlio de Mesquita Filho (Unesp). É bacharel em
Letras com habilitação em Tradução pela mesma instituição. Atualmente é professora na mesma universidade. É tradutora pública e intérprete comercial no estado de São Paulo desde 2000. É professora assistente Língua francesa da Universidade Estadual Paulista Júlio de Mesquita Filho, campus de São José do Rio Preto. 
Clarissa Prado Marini (CPM): A senhora foi a primeira tradutora de Antoine Berman no Brasil com a publicação de A prova do estrangeiro: Cultura e tradição na Alemanha romântica em 2002. Qual foi a motivação de se traduzir ineditamente em português L'Épreuve de l'étranger: Culture et tradition dans l'Allemagne romantique (1984)?

Maria Emília Pereira Chanut (MEPC): Quando iniciei o meu Mestrado em 1998, tive a sorte de ser a primeira orientanda do Prof. Dr. Marcos Siscar, na Unesp de São José do Rio Preto. Ele acabava de chegar de Paris com o exemplar de L'épreuve de l'étranger. Como ele sabia que eu era ex-aluna do curso de Tradutor, com habilitação em francês, e que desejava trabalhar com teoria da tradução, propôs-me a tradução do livro de Antoine Berman que, naquele momento, era considerado o maior teórico da tradução na França. Aceitei o desafio e confesso que foi a experiência mais grandiosa e apaixonante de minha vida acadêmica.

\section{CPM: Qual foi o projeto de tradução idealizado para traduzir o livro de Berman?}

MEPC: Houve a necessidade de um estudo profundo de cada um dos autores alemães e de suas teorias para que eu pudesse, em alguns momentos, compreender em profundidade as ideias de Berman e de seus comentários em torno das teorias do romantismo alemão que estão na origem de todo o pensamento ocidental sobre a tradução poética.

CPM: Além dos conceitos complexos propostos na obra, que outros elementos tornaram essa tradução desafiadora? Qual foi o seu maior desafio na tradução de L'Épreuve de l'étranger? MEPC: O maior desafio foi, sem dúvida, o próprio título, que sintetiza toda a genialidade do autor em torno da tradução poética como o "estranho-estrangeiro". Tanto a palavra "épreuve" quanto a palavra "étranger" sugeriam esse desafio ao tradutor, que se vê diante da impossibilidade de traduzir toda a poeticidade e riqueza de sentidos contidas na palavra poética.

CPM: Como foi a repercussão da publicação da sua tradução de L'Épreuve de l'étranger?

MEPC: Infelizmente, na época, eu não tinha a consciência da dimensão e da importância desse trabalho, que hoje auxilia tantos estudantes e pesquisadores não francófonos. Iniciei imediatamente o doutorado, cuja tese teve por objeto outro autor, Armand Robin, um poeta bretão que, aliás, foi redescoberto por Berman em L'épreuve de l'étranger. Eu sempre me interessei por estudos originais, pelo ineditismo, por buscas arqueológicas, como ocorreu nos dois casos, em que precisei ir até a França para obter materiais. Lembrando que 1998 foi o ano em que eu pude ter o primeiro acesso à Internet em minha residência, e ainda não existiam o 
Google e outras ferramentas, era tudo muito mais difícil. A repercussão ficou mais restrita aos pesquisadores que obtinham o exemplar em feiras de congressos, pois a compra on-line ainda era incipiente. Pelo que sei, não foi lançada nova edição e os exemplares usados dobraram de preço no site Estante Virtual.

CPM: A senhora teve acesso às traduções para o inglês The experience of the foreign: Culture and Translation in Romantic Germany (por Stefan Heyvaert, 1992) e para o espanhol La prueba de lo ajeno: Cultura y traducción en la Alemania romântica (por Rosario García López, 2003)? Chegou a consultá-las?

MEPC: Como acabo de explicar, há quase 20 anos não tínhamos essa facilidade que a Internet nos proporciona hoje. Eu não tive acesso a nenhuma delas.

CPM: Sua experiência como tradutora é mais ligada à tradução de que tipo de texto? Quando da realização da tradução da obra de Berman, a senhora tinha familiaridade com a prática de tradução de textos teóricos?

MEPC: Sou tradutora juramentada desde o ano de 2000. Desde então, trabalho apenas nesta especialidade. Quando traduzi Berman, eu não tinha nenhuma experiência com esse tipo de prática, tanto no que se refere ao conteúdo quanto ao fato de se tratar de um livro de 300 páginas. Depois deste, traduzi um livro sobre Filosofia da Educação, também para a Edusc.

CPM: De que forma a tradução de outros tipos de textos se relaciona com a tradução de textos teóricos, a seu ver?

MEPC: Berman influenciou radicalmente o meu percurso profissional e acadêmico no que diz respeito a minha postura tradutória e à reflexão sobre o traduzir. A questão ética, que foi o ponto central de minha reflexão no Mestrado, acompanhou todo o meu trabalho teórico e prático a partir das teorias de Berman. Mantenho até hoje uma postura bastante atrelada ao "respeito" pelo original, embora eu tenha a consciência da obrigação de me afastar da literalidade e de me adequar ao vernáculo em traduções mais técnicas. Esse assunto foi objeto de vários artigos meus.

CPM: Quando começou a empreitada da tradução de L'Épreuve de l'étranger, a senhora estava vindo de uma formação universitária em tradução. Durante o curso já se falava em 
Antoine Berman na universidade? Quais eram os teóricos apresentadas aos alunos na época da sua graduação?

MEPC: Eu retomei os meus estudos acadêmicos bem mais tarde, aos 35 anos, após ter morado em outras cidades e na França por vários anos. Portanto, na época da graduação nem se falava sobre teoria da tradução, não tínhamos essa disciplina, não havia iniciação científica, nem pesquisa na graduação. Me formei em 1982 e L'Épreuve de l'étranger é de 1984.

CPM: A tradução do livro de Berman fez parte do seu trabalho de mestrado. Ainda hoje o tema da tradução de textos teóricos é pouco explorado nos Estudos da Tradução. Quais seriam os motivos para isso na sua visão?

MEPC: Realmente uma grande pena. Sou supervisora do Estágio obrigatório de tradução dos alunos de quarto ano, e os incentivo a traduzir textos teóricos da área de humanas, em teoria da tradução inclusive, mas na realidade hoje as pesquisas mais valorizadas pelos futuros tradutores e pelas agências de fomento são aquelas relacionadas à terminologia de textos técnicos e especializados, à elaboração de glossários terminológicos e à lexicografia.

CPM: Na sua opinião, de que forma a tradução de obras de teoria da tradução contribui para o desenvolvimento nos Estudos da Tradução no Brasil?

MEPC: Mais do que fundamental. Eu já verifiquei, praticamente todas as monografias, teses, trabalhos acadêmicos e artigos publicados no Brasil que fizeram referência à obra de Berman utilizaram a minha tradução. Sinto-me muito satisfeita por ter contribuído com os pesquisadores não francófonos ao facilitar-lhes a leitura de um livro tão importante e essencial para os estudos da tradução.

\footnotetext{
* Clarissa Prado MARINI - Doutora em Estudos da Tradução (2019) pela Universidade Federal de Santa Catarina. Mestre em Estudos da Tradução (2015) pela Universidade de Brasília. Bacharel em Letras - Tradução (2013) pela mesma instituição. Professora substituta do curso de Letras-Tradução-Francês na Universidade de Brasília. Brasília, Distrito Federal, Brasil.

Currículo acadêmico: http://lattes.cnpq.br/4474411320594145

ORCID: https://orcid.org/0000-0002-9398-9246

E-mail: clarissamarini@gmail.com

** Maria Emília Pereira CHANUT - São José do Rio Preto, São Paulo, Brasil.

Currículo acadêmico: http://lattes.cnpq.br/9767513947933917

ORCID: https://orcid.org/0000-0003-0076-8944

E-mail: emilia.chanut@unesp.br
} 